\title{
Estudio del Armamento prerromano en la península ibérica a través de los textos clásicos
}

\author{
M. ${ }^{a}$ Paz Garcia-Gelabert Perez *
}

Los autores grecolatinos que escribieron sobre la peninsula convienen en un mismo parecer acerca de las diversas tribus que la poblaban antes de la conquista romana. Según estos autores los componentes de las tribus celtiberas, iberas, cántabras, astures, lusitanas, etc., eran anárquicos, amantes de la libertad y de las armas, activos, belicosisimos (Ptolom. Apotel. 64, 13); hombres frugales, trabajadores, dispuestos a morir por la libertad (Just. 44, 2,1), que prefieren la guerra a la paz y guerrean entre sí, cuando no hay enemigo de fuera (Just. $44,2,2$ ), y quieren más a sus armas que a su vida (Just. $44,2,5$ ). Su división y orgullo no les permitia unirse en lazo común (Estr. III, 4, 3). Eran tribus fuertes de una civilización joven de extraordinaria vitalidad y resistencia y un indomable orgullo y amor a la libertad. Preferian morir a verse despojados de sus armas y sometidos a esclavitud. Durante las guerras de conquista romana, a la que los hispanos opusieron tenaz resistencia- Hispania, según Livio $(28,12,10)$ fue la primera de las provincias del continente en recibir a los romanos y la última en ser domada-, los escritores grecolatinos han transmitido numerosos episodios que atestiguan que el deponer las armas era para los indigenas hispanos peor que la muerte (Apiano, Iber 31 y 77; Livio 34, 17; Diodoro 33, 24 y 33, 16; Floro 1, 34, 3; Dion Casio fr.75; de vir. III. 71; Estrabon III, 4, 17-18). Los habitantes de numerosas ciudades repartidas por la geografia peninsular, asediados por púnicos o romanos, prefirieron darse muerte voluntariamente a caer

\footnotetext{
* UNED
} 
en manos del enemigo, quien les someteria a esclavitud, ejemplo de ello son las ciudades de Sagunto (Livio, 21, 7, 8, 11, 12, 14, 15; Zonaras, 8, 21; Apiano, Iber 10; Diodoro, 25, 15; Frontino, 31, 10, 4; Orosio, 4, 14, 1; Val. Máx. 6, 6 ex.1; Floro, 1, 22, 3); Astapa (Livio, 28, 22-23; Apiano, Iber 33); Numancia (Apiano, Iber 95-98; Estrabón, 162; Livio, per. 57, 59; Cicerón, De off., 1, 11, 35; Horacio, Carm. 2, 12, 5; Veleyo, 2, 4, 2; Val. Máx. 7, 6, ext. 2 y 7; 2, 7, 1; Séneca, De Ira 11, 7; Epist. 7, 4, 13; Ps. Frontino 4, 5, 23; Floro, 1, 34, 11; Orosio 5, 7, 2-18); Calagurris (Orosio, 5, 23, 14; Salust., Hist. 3, 87; Val. Máx. 7, 6, ext. 3; Floro, 2, 10, 9).

Las armas en manos de estos hombres, animados por un deseo intenso de libertad e independencia, tuvieron una efectividad prodigiosa, que si bien no lograron evitar la conquista romana, lograron detenerla parcialmente durante aproximadamente doscientos años y preocupar seriamente al Imperio, pues como escribe Cicerón (De off. I, 38), aludiendo a las bajas terribles que los celtíberos causaban en las legiones, "se luchó no sólo por la victoria, sino por la existencia".

El armamento usado por los hispanos era simple y ligero, adecuado a su estilo de combate, muy particular y que desde un principio desconcertó y admiró a los romanos. En las contiendas, que entendian de forma peculiar, no se exponian frente al enemigo en grandes ejércitos, que tampoco poseian, sino que utilizaban el sistema de guerrillas, con gran movilidad, lanzándose al combate en tropel, saltando según su costumbre (Livio 23, 26). Por su austeridad, fortaleza física y agilidad fueron guerreros muy apreciados por los púnicos, que los alistaron en sus ejércitos como mercenarios. Del caracteristico modo de combatir se ocuparon los escritores clásicos: Estrabón: (III, 4, 15) «Los iberos en sus guerras, han combatido, pudieramos decir, como "peltastai", porque luchando al modo de los bandoleros, iban armados a la ligera y llevaban sólo, como hemos dicho de los lusitanos, jabalina, honda y espada. La infantería llevaba también mezcladas fuerzas de caballería; los cabalios están habituados a escalar montañas y a flexionar rápidamente las manos a una orden dada en momento oportuno" "No es costumbre privativa de los iberos la de montar dos en un mismo caballo, de los cuales uno, llegado el momento del combate, lucha como peón" (III, 4, 18). "Dicen que los lusitanos son diestros en emboscadas y persecuciones, ágiles, listos y disimulados" (III, 3,6). Livio trata del mismo tema: "Más acostumbrados (los españoles) a los montes y más aptos para correr saltando por entre rocas y peñascos a lo que les ayudaba la ligereza de sus armas tanto como la velocidad de sus cuerpos" $(22,18,2)$ "... la velocidad de los celtíberos, cuya costumbre en las batallas es atacar corriendo" $(28,2$, 39, 31). Plutarco (Fab. Max. 7) «... hasta que Anibal lanzó al ataque a 
los iberos, expertos en escalar montañas, ligeros y rápidos", en la vida de Sertorio (12) los define como "hombres veloces como el viento que toleran el hambre y un género de vida sin fuego ni tiendas". Y Frontino $(2,5,31)$ los define como avezadísimos a las estratagemas guerreras y ligeros. Polibio (frag. 95) escribe sobre la manera de combatir los celtíberos: "son buenos luchadores a pie como a caballo; cuando ven que sus infantes ceden, descabalgan y dejan los caballos dispuestos en formación; al efecto disponen unos pequeños clavos al extremo de las riendas, los que clavan en el suelo enseñando a los caballos a no moverse de la fila hasta que ellos vuelven y arrancan los clavos". Livio (27, 33; 29, 11) hace extensiva a los ilergetes esta modalidad de lucha de la caballeria celtíbera. La caballería hispana se menciona en numerosas ocasiones, siempre alabándola. Fue utilizada primeramente como tropa mercenaria por los púnicos y más tarde por los romanos. Anibal se sirvió de ellos en la segunda guerra púnica. La caballeria hispana la citan los historiadores de esta guerra varias veces: en el cruce del Po (Livio 21, 47) y en la batalla de Cannas, Aníbal situó la caballería ibérica y celta frente a la romana (Polibio 3, 113, 6-7; Livio 22, 46, 1, 3). Al referirse a las correrías invernales del año 217 a.C., Livio $(21,7,5)$ expresamente escribe que la caballeria celtibera y lusitana era superior a la númida. Polibio $(3,110,2 ; 117,4 ; 9,3,9)$ repetidas veces da como causa de la superioridad de los cartagineses sobre los romanos el hecho de que aquéllos dispusieran de mejor caballería. Livio $(27,14,5)$, por su parte, afirma que la fuerza principal del ejército de Anibal eran las tropas hispanas.

Se lanzaba, pues, el guerrero hispano al combate corriendo, como ampliamente queda atestiguado, empuñando las armas, sacudiendo las largas cabelleras que a propósito llevaban sueltas (Apiano, Iber 67 - 69; Lucilio 288), -los cántabros ceñian la frente con una banda (Estrabon III, 3, 7)-; gritando y entonando cánticos guerreros (Apiano, Iber 67-69; Val. Max. 2, 6, 11), considerados al oído de los romanos como bárbaro ulular (Silio Itál. 3, 346). Las mismas tribus indígenas se aterrorizaban a veces con el grito de guerra de otras tribus rivales, como les sucedió a los suesetanos, aliados de Catón en el año 195 a.C., contra los lacetanos (Livio 34, 20; Frontino, 3.10, 1). También hacian ondear los estandartes y las enseñas militares que los distinguian, cuya existencia está atestiguada (Livio 23,$26 ; 24,21 ; 25,33 ; 31,49,7 ; 34,20 ; 39,31 ; 40,33 ; 40$, $39 ; 40,18,6$; Silio Itál. 5, 335-340). Es, por tanto, de suponer el pavor de que se verían acometidos sus enemigos, romanos y púnicos sobre todo, cuya forma de combatir respondía a un modo de vida con un mayor grado de civilización. 
Después de dar este breve repaso a su manera de combatir, hora es ya de que se describa el armamento de estos hombres. Como indique era simple y ligero. Como armas ofensivas usaban las siguientes:

Espada. La más comúnmente usada en el centro peninsular, es decir por las tribus celtiberas, carpetanas, etc., era la espada recta y corta. El puño tiende a ser redondeado, siendo el extremo superior del mismo de frontón o antenado, con una variedad esta última modalidad de tipo muy sensible, desde dos antenas diversificadas, hasta pequeños cuernos o bolas que aparecen en el inicio de la empuñadura. La ornamentación del puño es muy variada. Se conseguía por medio de placas de hueso, madera labrada, marfil o bien mediante repujado a base de hilos de plata, realizando, a veces, magníficos dibujos geométricos a base de círculos, espirales, meandros. Esta espada fue muy efectiva para la lucha cuerpo a cuerpo, para herir hincando la espada, 10 mismo en golpe hacia arriba en el vientre que para abajo en el pecho y de lado en los costados. Las vainas debian ser de cuero o madera, con los rebordes laterales de hierro, así como la parte superior. Frecuentemente llevaba una decoración semejante a la de la empuñadura.

Los pueblos iberos utilizaban la espada falcata, que es de forma curva y un solo filo, antecedente de los sables, que sirve para atacar con punta y filo. La falcata está constituida por un alma de hierro que tiene dos partes, la hoja y la empuñadura. La hoja presenta en ambas caras una serie de canalillos destinados a aumentar la gravedad de las heridas. Suele ser más larga que la espada descrita arriba. Es muy adecuada para el combate cuerpo a cuerpo. La empuñadura está guarnecida de manera, hueso o metal, con las mismas caracteristicas decorativas que en las espadas cortas. A los adornos, sobre todo de decoraciones geométricas, eran muy aficionadas las tribus peninsulares, en especial las del interior. Estas decoraciones también se aplicaban, según Varrón (Saturae Menippeae Rel. 170) a los escudos.

Puñal. Diodoro $(5,33)$ alude a los puñales hispanos, concretamente a los celtiberos "se sirven también para el cuerpo a cuerpo de puñales con una longitud de nueve pulgadas". Fue usado en términos generales para rematar. Puede ser de hoja triangular muy ancha en la guarda de la empuñadura. $O$ bien puede ser, y es éste el caso más frecuente, afalcatado. Los puñales afalcatados llevan el mango adornado con hueso, madera o bien en metal, o en algunos casos, como en las espadas, repujado con hilos de plata. A veces la vaina de las espada lleva adosado un puente en la parte alta para dejar hueco a la vaina del puñal. Estrabón (III, 3, 6) alude a los puñales cuando relaciona el armamento de los lusitanos. 
Lanza. Fue muy utilizada por todos los pueblos hispanos. Las más frecuentes puntas de lanza tienen una nervadura central y cono de enmangue circular. La lanza está formada por tres partes, la punta de hierro, el asta de madera y el regatón o contera también de hierro, cuya punta afilada permitía hincarla en tierra. Podía usarse en el combate cuerpo a cuerpo o ser lanzada como una jabalina, según Estrabón ( $X, 1$, 12). Aunque en general las puntas de lanza y regatones son de hierro, parece que los lusitanos usaban, al menos algunos, lanzas con punta de bronce (Estrabón III, 3, 6).

Falárica. Es una arma arrojadiza, muy común en el armamento ibérico. Livio $(21,8)$, con motivo de la narración del sitio de Sagunto la describe "...usaban los saguntinos un arma arrojadiza llamada falárica, cuya asta era de abeto y redonda en toda su extensión, excepto en el extremo, donde se colocaba el hierro: éste, cuadrado, como en el "pilum", estaba rodeado de una estopa empapada en pez. El hierro era largo, de tres pies, para poder traspasar la armadura y el cuerpo. Pero aún en el caso de quedar clavado en el escudo y no penetrar en el cuerpo, llenaba de terror, pues como se lanzaba encendida la estopa y su carrera avivaba su llama, obligaba al soldado a despojarse de sus armas y exponerse indefenso a los golpes siguientes.

Soliferreum. Es una larga barra de hierro, engrosado en la parte media, para empunarla comodamente. Uno de los extremos acaba en punta cónica, mientras que el otro acaba en punta de lanza, con pequenas barbas en forma de anzuelo, lo que origina su nombre griego de "saunion" ganchudo. Cuando los autores clásicos al narrar determinados hechos bélicos se refieren a los dardos y venablos pueden estar aludiendo al "soliferreum» o bien a verdaderos dardos o venablos de madera endurecida al fuego, como los usados por los baleares (Estrabon III. $5,1)$.

Flecha. Las puntas de flecha, generalmente están hechas en hierro. Suelen tener un fuerte nervio central y aletas más o menos marcadas.

Hacha de doble filo. No parece ser muy usada en Hispania, salvo por los cántabros. Silio Itálico $(16,46-65)$ describe la lucha del cántabro Laro el cual llevaba un hacha doble, de dos filos y en la cabeza una gorra de pellejo.

Honda. Era el arma caracteristica de los habitantes de Baleares. La descripción de los indígenas baleares y su armamento hecha por Estrabón (III,5,1) es muy ilustrativa, por lo que me atengo a ella "... en el combate se presentan sin ceñir, teniendo el escudo de piel de cabra en una mano y en la otra una jabalina endurecida al fuego; raras veces una 
lanza provista de una pequeña punta de hierro. Alrededor de la cabeza llevan tres hondas de junco negro, de cerdas o de nervios: una larga, para los tiros largos; otra corta para los cortos y otra mediana, para los intermedios. Desde niños se adiestran en el manejo de la honda, no recibiendo el pan si no lo han acertado antes con ella». Del proyectil de la honda baleárica dice Ovidio en su Metamorfosis $(11,727)$, que es tal la velocidad que le imprimen, que se calienta hasta fundirse cuando es de plomo, lo cual constituye lógicamente una exageración. Según Estrabón (III, 4,15$)$ también los iberos utilizaban la honda, pero en general en los textos clásicos, cuando se alude a esta arma, se la asocia con los guerreros baleares.

En cuanto a elementos defensivos, los hispanos no se protegian, en general, el cuerpo con piezas metálicas. La mayor parte solian emplear corazas de lino, aunque algunos utilizaban cotas de malla (Estrabón III, $3,6)$ y otros grandes discos, denominados faleras, que defendian pecho, espalda y hombros. A veces se protegían las piernas con perneras (Estrabón III, 3, 6).

El énfasis de la defensa personal se cifraba en el escudo y en la pericia de su manejo. Narra Diodoro $(5,34)$ : «los más valientes de los iberos son los llamados lusitanos. Llevan en batalla un pequeño escudo que está hecho por completo de cuero trenzado y puede proteger el cuerpo con mucha eficacia, debido a su solidez. Este escudo to hacen girar con mucha habilidad en las batallas y así consiguen interceptar toda clase de armas que se les arroje".

Entre las tribus hispanas se emplearon dos tipos de escudos: la "caetra», circular y cóncava, el más común. Estrabón (III, 3,6) lo describe así: "es pequeño, de dos pies de diámetro y cóncavo por su lado anterior, lo llevan suspendido por delante con correas y no tiene, al parecer, abrazaderas ni asas". Numerosos autores aluden a la "caetra" y a los soldados armados a la ligera, que portaban este escudo, como Polibio, 11, 22; 11, 23; Livio, 28, 2; César, B.c. 1, 39; 1, 48, 1, 78; Tácito, Agr. 36; Lucano, VII, 232; acerca de los galaicos y de los iberos Silio Itálico escribe que los hombres de ambos pueblos marcan el ritmo del baile de guerra y del canto golpeando sobre el escudo $(3,347-349 ; 10$, 229-230). Y el "scutum", oblongo, rectangular, que cubría las dos terceras partes del cuerpo. Diodoro $(5,33)$ escribe acerca de los escudos: "que algunos de los guerreros iban armados con escudo de tipo galo, oblongo y de peso ligero, mientras que otros llevaban el escudo circular del mismo tamaño que el usado por los griegos». Livio $(28,2)$ y César (B.C. 1,39), entre otros, citan a los "scutata" hombres armados con grandes escudos. 
Los cascos más usualmente utilizados eran los de cuero o tejidos de nervios (Estrabón III,3,6). También, para proteger la nuca, peinaban el cabello con trenzas que recogian atrás. Algunos indígenas, tal vez ya por influencia romana, llevaban cascos de triple cresta (Estrabón III, 3, 6).

El hierro con el que estaban fabricadas las armas hispanas era, en general, de excelente calidad. El buen temple, el arte de los herreros que fabricaban estas armas pronto llegó a Roma, donde fue elogiado por todos aquellos que se ocupaban de la Península, como Silio Itálico que alude a los galaicos como hábiles armeros $(2,417 ; 4,326)$, e indica que los habitantes de Carthago Nova son obreros hábiles en la industria del armamento, hecho que se destaca también en Polibio $(10,8,5 ; 17,9 \mathrm{y}$ $10)$ y en Livio $(26,47,2)$. Pomponio Porfirio $(40,3)$ alaba a los armeros ibéricos. Polibio (fragm. 95) escribe que los celtíberos sobresalen en mucho entre los demás pueblos en la fabricación de espadas, hecho en el que coincide Plutarco (de garr. 17). Esta destreza se puso de manifiesto en el hecho de haber ordenado Sertorio en el año 77 a.C. a todas las ciudades de Celtiberia que fabricasen armas según sus posibilidades (Livio, frag. 91). Grattio (Cyneg. 341) menciona un cuchillo de Toledo, testimonio de que ya entonces, como hoy, en Toledo se fabricaban buenas armas. Cicerón (De nat. deorum I, 84) escribe que los indigenas de la Peninsula veneraban a Vulcano, dios del fuego y de los herreros, bajo otro nombre, lo cual es muy propio de estas poblaciones donde existían muchas personas que trabajaban el metal.

Armas hispanas como la espada y el puñal fueron usadas por las legiones romanas, a causa de su eficacia, como indica Polibio (fragm. 95) "los romanos desde tiempos de Aníbal abandonaron las espadas de sus antepasados, cambiándolas por las de los españoles. Pero si pudieron imitar la forma, nunca lograron alcanzar la calidad del hierro y la perfección de la factura". De la calidad de las espadas españolas hablan por sí mismos los dos párrafos que siguen, de Séneca (de benef. 5,24) y Livio $(31,34,4)$, respectivamente: «Defendía un pleito ante el divino Julio un cierto veterano suyo al que no reconoció a lo cual aquél respondió: razón tienes de no reconocerme, César. Pues en aquella ocasión estaba todavia entero. Después en Munda me sacaron un ojo en la refriega y me descubrieron los huesos del cráneo. $Y$ tampoco reconocerías aquel casco si lo vieses, porque un sable español lo partió; "pero cuando vieron los cuerpos despedazados por la espada española, brazos cortados del hombro, cabezas separadas del cuerpo, truncada enteramente la cerviz, entrañas al descubierto y toda clase de horribles heridas, aterrados se preguntaban contra qué armas y contra qué hombres tenian que luchar». Tratan también sobre la espada hispana Floro (epit. 1, 23, 
9) y Livio, de nuevo $(38,21,21)$. Al puñal español hace una alusión Cicerón en Oratio in toga candita.

Gracias a Diodoro $(5,33,3-4)$ se conoce el modo de fabricar las espadas: «los celtíberos... tienen un modo muy particular de preparar las armas... meten bajo tierra las láminas de hierro y alli permanecen hasta que, con el tiempo, la parte débil del hierro se consume por la herrumbre y se separa de la parte más dura; de ésta se sacan magníficas espadas y otros instrumentos guerreros. No hay espada, ni casco, ni hueso que resista a su golpe».

Philón (mechaniké syntasis IV-V), describe asimismo la forja de las armas: para probarlas, agarraban con la derecha la empuñadura y con la otra mano la punta, colocaban luego la hoja transversal sobre la cabeza, tiraban luego para abajo de ambas extremidades hasta que se tocaban con los hombros y luego las soltaban. La hoja permanecia recta, aunque esta prueba se repitiera varias veces. Esta flexibilidad se debia a que el hierro era muy puro y estaba bien trabajado al fuego. Se forjaba en frío y no a martillazos, combinando la acción del fuego y del frío. Marcial (1, $49,4)$, que alaba las armas celtiberas por la buena calidad de su hierro, que venía del Moncayo, muchas de las cuales se forjaron en Bílbilis, creia que el agua fría del Jalón era a propósito para su temple $(1,49,12$, también 4,$55 ; 14,35)$. En otro párrafo $(14,33)$ se ocupa del puñal ibérico, forjado en Bílbilis con el hierro del Moncayo y el agua fría del Salo (Jalón).

El armamento de los pueblos celtíberos, oretanos, lusitanos, iberos, etc., se conoce con bastante fidelidad, puesto que se ha hallado en sus necrópolis, como parte integrante de los ajuares funerarios de los guerreros. También se ha hallado representado en la escultura, entre la que destacan las de Porcuna, la antigua Obulco, localizada por Ptolomeo (2, $4,10)$ en el territorio de los túrdulos; las de tema bélico de la Alcudia de Elche; los exvotos, estatuillas de pequeño tamaño, encontradas en los santuarios ibéricos de Collado de los Jardines, Castellar de Santisteban, Jaén y Nuestra Señora de la Luz, Murcia y los del Salobral, Albacete y la Bastida de les Alcuses, Mogente, Valencia; y las esculturas de guerreros lusitanos, que actualmente se encuentran en los museos de Guimarães y Etnológico de Lisboa. En los relieves, como los de Osuna, Sevilla. En las estelas funerarias de Lara de los Infantes y Clunia, Burgos; Calaceite, Teruel y las localizadas en el término de Villatuerta, cerca de Estella, en el término de Sos del Rey Católico y en Palermo, Caspe. En el alto relieve de la Albufereta, Alicante. En pinturas sobre cerámica, como en los vasos de San Miguel de Liria, de Archena, de Oliva y de Numan- 
cia. En los trabajos sobre metal, pátera de Tivisa y diadema de Oscos. $Y$ en numismática, sobre todo en la serie del jinete ibérico.

Además, y a esta fuente únicamente me remito en el presente estudio (el análisis de la representación del armamento en la plástica es objeto de otro trabajo), el armamento se menciona repetidamente en los escritos antiguos, no sólo en aquéllos que relatan la conquista de Hispania por Roma sino en aquéllos que describen las actuaciones de los hispanos como mercenarios en los ejércitos púnicos y romanos y las primeras incursiones de estos ejércitos en tierras hispanas. En tales textos se va desgranando una serie de episodios bélicos, en los que el guerrero hispano cobra una dimensión heroica, bien como mercenario o empeñado en la sangrienta contienda en defensa de su tierra y libertades, contra unos enemigos muy superiores en número, aunque no en bravura.

Las espadas se citan ya durante el asedio y toma por Aníbal de Salmantis (Salamanca) en el año 221-220 a.C., cuando las mujeres indíjenas las sacaron de la ciudad envueltas en sus túnicas para entregárselas a los hombres desarmados (Plutarco, Virt. Mul. 248e; Polieno 7,48). Puñales y espadas regaló Escipión a los niños indígenas después de haber tomado Carthago Nova a los púnicos en el año 209 a.C. (Polibio $10,18,3)$. Las espadas se nombran también en el encuentro de los ejércitos de Hannon y Magón contra el de Silano enviado por Escipión. En este episodio ocurrido en el año 207 a.C, los mercenarios celtíberos que luchaban en el bando púnico acometen con sus espadas a los romanos (Livio 28, 2). Con espadas mataron los lusitanos Audax, Ditalcon y Minuro a Viriato (Diodoro 33,21). De un solo golpe de espada un lusitano cortó la cabeza de un jinete romano y atravesó con una lanza el caballo de otro (Orosio 5, 4, 5). Espada en mano escoltaba a César su guardia personal de iberos (Suetonio, Cesar 86; Apiano, B.c. 2.109).

Con mayor frecuencia que las espadas, puñales o cualquier otro elemento bélico, en las fuentes clásicas se hace mención a las armas arrojadizas, lo que viene a indicar que eran las más utilizadas por los hispanos, hecho que está conforme con su sistema de lucha en guerrillas. Venablos, dardos y jabalinas son citados muy a menudo, tal vez como sinónimos de una misma pieza o, en otro caso, como armas muy similares. Algunas citas quizás se refieran a los "soliferrea" que nombra Livio $(34,14,10)$ en el año 195 a.C., como lanza ibera junto a la falárica (el "soliferreum" también es citado por M. Verrio Flacco 384,34 y Varrón, $X, 25,2)$. Amilcar encontró la muerte en el invierno del 229-228 a.C. en el río Vinalopó alcanzado por un dardo ibero (Tzetzes. Hist.I,27; Diodoro 25, 19). En el sitio de Sagunto, año 219 a.C. los ocupantes de la 
plaza arrojaban sin cesar dardos y flechas a los púnicos, hiriendo una de estas últimas a Aníbal en una pierna (Livio 21, 7). En el año 208 a.C. Escipión enfrentado a Asdrúbal no lejos de Baecula, es recibido por las tropas púnicas y auxiliares indígenas con una lluvia de proyectiles, dardos y piedras (Livio 27, 18). En los hechos bélicos de los años 186-185 a.C. el pretor $\mathrm{C}$. Calpurnio se enfrentó a los celtíberos, los cuales lanzándose corriendo a la lucha envolvieron al enemigo en sus dardos (Livio 39,31). Los habitantes de Cauca, lucharon contra Lúculo en el año 151 a.C. hasta que los dardos les faltaron (Apiano, Iber 50-52). Marcial $(4,55,20)$ habla de los silai, situados en las cercanias de Bílbilis, célebres por su habilidad en cazar con dardos.

Los venablos ya se citan en la batalla de Hibera año 215 a.C., cuando Livio $(23,29)$ narra como los soldados mercenarios de los púnicos, lanzan los venablos sobre las tropas romanas, y viceversa. En Munda (214-212 a.C.) Escipión recibió un lanzazo proveniente de las filas cartaginesas; por su parte, de las filas romanas se lanzaron abundantísimos venablos que acribillaron a 39 elefantes. En este párrafo no se aclara si los venablos fueron lanzados por las tropas mercenarias o por las romanas (Livio 24, 21). Las armas arrojadizas, sin especificar cuales, eran muy empleadas por los cántabros y astures, como se desprende de un párrafo de Dion Casio $(53,25,2)$, en el que describe las guerras entre estos pueblos y Augusto.

En cuanto a las lanzas, en el párrafo en el que Plutarco alude a las mujeres de Salmantis, las cuales tomaron las espadas entre sus vestidos y las sacaron de la ciudad, cita de entre ellas a una que, demostrando tanto valor como los guerreros, arrancó la lanza a un intérprete, llamado Badón, que presumiblemente sería indígena y le hiere con ella a pesar de su coraza (Virt. Mul. 248 e). En esta descripción histórica de Plutarco se especifican dos tipos de armas, la espada y la lanza y un elemento defensivo, al que los autores no suelen aludir a menudo, la coraza. En el año 74 a.C., en las guerras sertorianas, los soldados de Sertorio exigian la lucha, desnudando los hombros y blandiendo las lanzas (Frontino $2,1,3)$. Muchos de estos soldados, celtiberos la mayor parte, abandonaron a Sertorio y se pasaron al bando de Metelo (Apiano, B.c. 1, 112), por lo que Sertorio exasperado trató a muchos crueimente. A pesar de esta crueldad achacable a los ultimos años de su vida, Sertorio confiaba en estos soldados celtiberos, hasta el punto de que llevaba siempre consigo lanceros de este pueblo. Durante el enfrentamiento de Metelo a las tropas sertorianas aquél fue herido por un dardo, probablemente lusitano, de los que escribe Valerio Máximo $(9,1,5)$ que eran el terror de los ejércitos romanos (sobre Metelo herido por un dardo, tambien Putarco, 
Sert. 21). A las lanzas lusitanas alude Seneca (de se ad patriam 11), y a las mismas armas, sin especificar tribu, Varrón $(10,25,2)$.

Las faláricas, además de la descripción que proporciona Livio (21, $8)$, son mencionadas por Silio Itálico $(1,351)$; Nonio Marcelo $(3,891)$; Varrón $(10,25,2)$, el cual también cita una semifalárica únicamente aludida aquí, que pudo ser una falárica pequeña; Virgilio (Aen. IX. 705); Grattio (Cyneg. 341); Verrio Flacco $(78,20)$ y Lucano (VI, 198), aunque este autor emplea el nombre de falárica para un proyectil arrojado por una catapulta romana.

Finalmente, como arma arrojadiza hay que catalogar las hondas, o mejor dicho las piedras impulsadas por las hondas, en cuyo manejo eran expertos los indígenas de Baleares, de los que escribe Livio (per.60) que son llamados baleares o por su arte de lanzar el dardo - también utilizaban jabalinas de madera endurecidas al fuego (Estrabón III, 5, 1) -0 por descender de Balio, compañero de Hércules. Floro $(1,43)$ indica que eran hombres violentos y salvajes que apenas se atrevian desde los riscos a contemplar el mar... Cada uno luchaba con tres hondas, e incide en lo narrado por Estrabón que no recibian el alimento de su madre si antes no habian dado en el blanco que ellas mismas les indicaban. Livio $(28,37)$ indica que aquel pueblo utilizaba principalmente la honda, en cuyo manejo sobresalia de los demás pueblos, aunque los lusitanos también debian ser diestros en ello (Claudio Cuadrigario, frag. 85). Polibio $(3,33,7)$, narrando la marcha a Italia de Anibal con mercenarios, cita a los baleares "los que propiamente se llaman honderos, pues el uso de esta arma ha dado nombre a esta gente y a la isla por ellos habitada". Livio $(21,21)$ también cita a los honderos baleares como mercenarios de los púnicos. Sobre el arma baleárica por excelencia trataron otros autores, asimismo, como Silio Itálico (3,365); P. Papinio Stacio (Achill. II, 134; Theb.X, 857); Ovidio (Metamorph. II, 727; IV, 709); Lucano (I, 229; III, 710); Flavio Vegecio Renato (I, 16) y Likofon de Chalkis (633) quien recoge noticias de Estrabón y Timeo. 